\title{
Issues in Translating Verb-Particle Constructions from German to English
}

\author{
Nina Schottmüller \\ Uppsala University \\ Joakim Nivre \\ Uppsala University \\ Department of Linguistics and Philology Department of Linguistics and Philology \\ nschottmueller@gmail.com \\ joakim.nivreelingfil.uu. se
}

\begin{abstract}
In this paper, we investigate difficulties in translating verb-particle constructions from German to English. We analyse the structure of German VPCs and compare them to VPCs in English. In order to find out if and to what degree the presence of VPCs causes problems for statistical machine translation systems, we collected a set of 59 verb pairs, each consisting of a German VPC and a synonymous simplex verb. With this data, we constructed a test suite of 236 sentences where the simplex verb and VPC are completely substitutable. We then translated this dataset to English using Google Translate and Bing Translator. Through an analysis of the resulting translations we are able to show that the quality decreases when translating sentences that contain VPCs instead of simplex verbs. The test suite is made freely available to the community.
\end{abstract}

\section{Introduction}

In this paper, we analyse and discuss German verb-particle constructions (VPCs). VPCs are a type of multiword expressions (MWEs) which are defined by Sag et al. (2002) to be "idiosyncratic interpretations that cross word bounderies (or spaces)". Kim and Baldwin (2010) extend this explanation in their definition of MWEs being "lexical items consisting of multiple simplex words that display lexical, syntactic, semantic and/or statistical idiosyncrasies".

VPCs are made up of a base verb and a particle. In contrast to English, where the particle is always separated from the verb, German VPCs are separable, meaning that the particle can either be attached as a prefix to the verb or stand separate from it, depending on factors such as tense and voice, along with whether the VPC is found in a main clause or subordinate clause.

The fact that German VPCs are separable means that word order differences between the source and target language can occur in statistical machine translation (SMT). It has been shown that the translation quality of translation systems can suffer from such differences in word order (Holmqvist et al., 2012). Since VPCs make up for a significant amount of verbs in English, as well as in German, they are a likely source for translation errors. This makes it essential to analyse any issues with VPCs that occur while translating, in order to be able to develop possible improvements.

In our approach, we investigate if the presence of VPCs causes translation errors. We do this by creating and utilising a dataset of 236 sentences, using a collection of 59 German verb pairs, each consisting of a VPC and a synonymous simplex verb, a test suite that is made freely available. We discuss the English translation results generated by the popular translation systems Google Translate and Bing Translator and show that the presence of VPCs can harm translation quality.

We begin this paper by stating important related work in the fields related to VPCs in Section 2 and continue with a detailed analysis of VPCs in German in Section 3. In Section 4, we describe how the data used for evaluation was compiled, and in Section 5, we give further details on the evaluation in terms of metrics and systems tested. Section 6 gives an overview of the results, as well as their discussion, where we present possible reasons why VPCs performed worse in the experiments, which finally leads to our conclusions in Section 7. An appendix lists all the verb pairs used to construct the test suite.

\section{Related Work}

A lot of research has been done on the identification, classification, and extraction of VPCs, with 
the majority of work done on English. For example, Villavicencio (2005) presents a study about the availability of VPCs in lexical resources and proposes an approach to use semantic classification to identify as many VPC candidates as possible. She then validates these candidates using the retrieved results from online search engines.

Many linguistic studies analyse VPCs in German, or English, respectively, mostly discussing the grammar theory that underlies the compositionality of MWEs in general or presenting more particular studies such as theories and experiments about language acquisition. An example would be the work of Behrens (1998), in which she contrasts how German, English and Dutch children acquire complex verbs when they learn to speak, focusing on the differences in the acquisition of VPCs and prefix verbs. In another article in this field by Müller (2002), the author focuses on nontransparent readings of German VPCs and describes the phenomenon of how particles can be fronted.

Furthermore, there has been some research dealing with VPCs in machine translation as well. In a study by Chatterjee and Balyan (2011), several rule-based solutions are proposed for how to translate English VPCs to Hindi, using their surrounding entities. Another paper in this field by Collins et al. (2005) presents an approach to clause restructuring for statistical machine translation from German to English in which one step consists of moving the particle of a particle verb directly in front of the verb. Moreover, even though their work does not directly target VPCs, Holmqvist et al. (2012) present a method for improving word alignment quality by reordering the source text according to the target word order, where they also mention that their approach is supposed to help with different word order caused by finite verbs in German, similar to the phenomenon of differing word order caused by VPCs.

\section{German Verb-Particle Constructions}

VPCs in German are made up of a base verb and a particle. In contrast to English, German VPCs are separable, meaning that they can occur separated, but do not necessarily have to. This applies only for main clauses, as VPCs can never be separated in German subordinate clauses. Depending on the conjugation of the verb, the particle can a) be attached to the front of the verb as prefix, ei- ther directly or with an additional morpheme, or b) be completely separated from the verb. The particle is directly prefixed to the verb if it is an infinitive construction, for example within an active voice present tense sentence using an auxiliary (e.g., muss herausnehmen). It is also attached directly to the conjugated base verb when using a past participle form to indicate passive voice or perfect tense (e.g., herausgenommen), or if a morpheme is inserted to build an infinitive construction using zu (e.g., herauszunehmen). The particle is separated from the verb root in finite main clauses where the particle verb is the main verb of the sentence (e.g., nimmt heraus). The following examples serve to illustrate the aforementioned three forms of the non-separated case and the one separated case.

Attached:

Du musst das herausnehmen.

You have to take this out.

Attached+perfect:

Ich habe es herausgenommen.

I have taken it out.

Attached $+z u$ :

Es ist nicht erlaubt, das herauszunehmen.

It is not allowed to take that out.

Separated:

Ich nehme es heraus.

I take it out.

Just like simplex verbs, VPCs can be transitive or intransitive. For the separated case, a transitive VPC's base verb and particle are always split and the object has to be positioned between them, despite the generally freer word order of German. For the non-separated case, the object is found between the finite verb (normally an auxiliary) and the VPC.

Separated transitive:

Sie nahm die Klamotten heraus.

*Sie nahm heraus die Klamotten. She took [out] the clothes [out].

Non-separated transitive:

Sie will die Klamotten herausnehmen.

* Sie will herausnehmen die Klamotten.

She wants to take [out] the clothes [out].

Similar to English, a three-fold classification can be applied to German VPCs. Depending on their 
formation, they can either be classified as a) compositional, e.g., herausnehmen (to take out), b) idiomatic, e.g., ablehnen (to turn down, literally: to lean down), or c) aspectual, e.g., aufessen (to eat up), as proposed in Villavicencio (2005) and Dehé (2002).

Compositional:

Sie nahm die Klamotten heraus.

She took out the clothes.

Idiomatic:

Er lehnt das Jobangebot ab.

He turns down the job offer.

Aspectual:

Sie aß den Kuchen auf.

She ate up the cake.

There is another group of verbs in German which look similar to VPCs. Inseparable prefix verbs consist of a derivational prefix and a verb root. In some cases, these prefixes and verb particles can look the same and can only be distinguished in spoken language. For instance, the infinitive verb umfahren can have the following translations, depending on which syllable is stressed.

VPC:

umfahren

to knock down sth./so. (in traffic)

Inseparable prefix verb:

umfahren

to drive around sth./so.

As mentioned before, there is a clear difference between these two seemingly identical verbs in spoken German. In written German, however, the plain infinitive forms of the respective verbs are the same. In most cases, context and use of finite verb forms reveal the correct meaning.

VPC:

Sie fuhr den Mann um.

She knocked down the man (with her car).

Inseparable prefix verb:

Sie umfuhr das Hindernis.

She drove around the obstacle.

For reasons of similarity, VPCs and inseparable prefix verbs are sometimes grouped together under the term prefix verbs, in which case VPCs are then called separable prefix verbs. However, since

\begin{tabular}{llll}
\hline & Simplex & VPC & Total \\
\hline Finite sentence & 59 & 59 & 118 \\
Auxiliary sentence & 59 & 59 & 118 \\
\hline Total & 118 & 118 & 236 \\
\hline
\end{tabular}

Table 1: Types and number of sentences in the test suite.

the behaviour of inseparable prefix verbs is like that of normal verbs, they will not be treated differently throughout this paper and will only serve as comparison to VPCs in the same way that any other inseparable verbs do.

\section{Test Suite}

In order to find out how translation quality is influenced by the presence of VPCs, we are in need of a suitable dataset to evaluate the translation results of sentences containing both particle verbs and synonymous simplex verbs. Since it seems that there is no suitable dataset available for this purpose, we decided to compile one ourselves.

With the help of several online dictionary resources, we first collected a list of candidate VPCs, based on their particle, so that as many different particles as possible were present in the initial set of verbs, while making sure that each particle was only sampled a handful of times. We then checked each of the VPCs for suitable simplex verb synonyms, finally resulting in a set of 59 verb pairs, each consisting of a simplex verb and a synonymous German VPC (see Appendix A for a full list). We allowed the two verbs of a verb pair to be partially synonymous as long as both their subcategorization frame and meaning was identical for some cases.

For each verb pair, we constructed two German sentences in which the verbs were syntactically and semantically interchangeable. The first sentence for each pair had to be a finite construction, where the respective simplex or particle verb was the main verb, containing a direct object or any kind of adverb to ensure that the particle of the particle verb is properly separated from the verb root. For the second sentence, an auxiliary with the infinitive form of the respective verb was used to enforce the non-separated case, where the particle is attached to the front of the verb.

Using both verbs of each verb pair, this resulted in a test suite consisting of a total of 236 sentences (see Table 1 for an overview). The following ex- 
ample serves to illustrate the approach for the verb pair kultivieren - anbauen (to grow).

Finite:

Viele Bauern in dieser Gegend kultivieren Raps. (simplex)

Viele Bauern in dieser Gegend bauen Raps an. (VPC)

Many farmers in this area grow rapeseed.

Auxiliary:

Kann man Steinpilze kultivieren? (simplex)

Kann man Steinpilze anbauen? (VPC)

Can you grow porcini mushrooms?

The sentences were partly taken from online texts, or constructed by a native speaker. They were set to be at most 12 words long and the position of the simplex verb and VPC had to be in the main clause to ensure comparability by avoiding too complex constructions. Furthermore, the sentences could be declarative, imperative, or interrogative, as long as they conformed to the requirements stated above. The full test suite of 236 sentences is made freely available to the community. ${ }^{1}$

\section{Evaluation}

Two popular SMT systems, namely Google Translate $^{2}$ and Bing Translator, ${ }^{3}$ were utilised to perform German to English translation on the test suite. The translation results were then manually evaluated under the following criteria:

- Translation of the sentence: The translation of the whole sentence was judged to be either correct or incorrect. Translations were judged to be incorrect if they contained any kind of error, for instance grammatical mistakes (e.g., tense), misspellings (e.g., wrong use of capitalisation), or translation errors (e.g., inappropriate word choices).

- Translation of the verb: The translation of the verb in each sentence was judged to be correct or incorrect, depending on whether or not the translated verb was appropriate in the context of the sentence. It was also judged to be incorrect if for instance only the base verb was translated and the particle was ignored, or if the translation did not contain a verb.

\footnotetext{
${ }^{1}$ http://stp.lingfil.uu.se/ ninas/testsuite.txt

${ }^{2}$ http://www.translate.google.com

${ }^{3}$ http://www.bing.com/translator
}

- Translation of the base verb: Furthermore, the translation of the base verb was judged to be either correct or incorrect in order to show if the particle of an incorrectly translated VPC was ignored, or if the verb was translated incorrectly for any other reason. For VPCs, this was judged to be correct if either the VPC, or at least the base verb was translated correctly. For simplex verbs, the judgement for the translation of the verb and the translation of the base verb was always judged the same, since they do not contain separable particles.

The evaluation was carried out by a native speaker of German and was validated by a second German native speaker, both proficient in English.

\section{Results and Discussion}

The results of the evaluation can be seen in Table 2. In this table, we merged the results for Google and Bing to present the key results clearly. For a more detailed overview of the results, including the individual scores for both Google Translate and Bing Translator, see Table 3.

In the total results, we can see that on average $48.3 \%$ of the 236 sentences were translated correctly, while a correct target translation for the sentence's main verb was found in $81.1 \%$ of all cases. Moreover, $92.2 \%$ of the base verb translations were judged to be correct.

By looking at the results for VPCs and simplex verbs separately, we are able to break down the total figures and compare them. The first thing to note is that only $43.2 \%$ of the sentences containing VPCs were translated correctly, while the systems managed to successfully translate $53.4 \%$ of the simplex verb sentences, showing a difference of around $10 \%$ absolute. The results for the verb transitions in these sentences differ even further with $71.6 \%$ of all VPC translations being judged to be correct and $90.7 \%$ of the simplex translations judged to be acceptable, revealing a difference of around $20 \%$ absolute.

Another interesting result is the translation of the base verb, where a correct translation was found in $93.6 \%$ of the cases for VPCs, meaning that in $22.0 \%$ of the sentences the systems made a mistake with a particle verb, but got the meaning of the base verb right. This indicates that the usually different meaning of the base verb can be misleading when translating a sentence that contains 


\begin{tabular}{lrrr}
\hline & Sentence (\%) & Verb (\%) & Base V. (\%) \\
\hline VPC & $102(43.2 \%)$ & $169(71.6 \%)$ & $221(93.6 \%)$ \\
Finite & $47(39.8 \%)$ & $80(67.8 \%)$ & $114(96.6 \%)$ \\
Infinitive & $55(46.6 \%)$ & $89(75.4 \%)$ & $107(90.7 \%)$ \\
\hline Simplex & $126(53.4 \%)$ & $214(90.7 \%)$ & $214(90.7 \%)$ \\
Finite & $59(50.0 \%)$ & $103(87.3 \%)$ & $103(87.3 \%)$ \\
Infinitive & $67(56.8 \%)$ & $111(94.1 \%)$ & $111(94.1 \%)$ \\
\hline Total & $228(48.3 \%)$ & $381(81.1 \%)$ & $435(92.2 \%)$ \\
\hline
\end{tabular}

Table 2: Translation results for the test suite summed over both Google Translate and Bing Translator; absolute numbers with percentages in brackets. Sentence $=$ correctly translated sentences, Verb $=$ correctly translated verbs, Base V. = correctly translated base verbs, Simplex = sentences containing simplex verbs, VPC $=$ sentences containing VPCs, Finite $=$ sentences where the target verb is finite, Infinitive $=$ sentences where the target verb is in the infinitive.

a VPC, causing a too literal translation. Interestingly, many of the cases where the resulting English translation was too literal are sentences that contain idiomatic VPCs rather than compositional or aspectual ones, such as vorführen (to demonstrate, literally: to lead ahead/before).

In general, the sentences that contained finite verb forms achieved worse results than the ones containing infinitives. However, the differences are only around $7 \%$ and seem to be constant between VPC and simplex verb sentences. Taking into account that the sentences of each sentence pair should not differ too much in terms of complexity, this could be a hint that finite verb forms are harder to translate than auxiliary constructions, but no definite conclusions can be drawn from these results.

Looking at the individual results for Google and Bing, however, we can see that Bing's results show only a small difference between finite and infinitive verbs, whereas the scores for Google vary much more. Even though the overall results are still rather worse than Google's, Bing Translator gets a slightly better result on both finite simplex verbs and VPCs, which could mean that the system is better when it comes to identifying the separated particle that belongs to a particle verb. Google Translate, on the other hand, gets a noticeably low score on finite VPC translations, namely $59.3 \%$ compared to $86.4 \%$ for finite simplex verbs, or to Bing's result of $76.3 \%$, which clearly shows that separated VPCs are a possible cause for translation error.

The following examples serve to illustrate the different kinds of problems that were encountered during translation.
Ich lege manchmal Gurken ein.

Google: Sometimes I put a cucumber. Bing: I sometimes put a cucumber.

A correct translation for einlegen would be to pickle or to preserve. Here, both Google Translate and Bing Translator seem to have used only the base verb legen (to put, to lay) for translation and completely ignored its particle.

\section{Ich pflanze Chilis an.}

Google: I plant to Chilis. Bing: I plant chilies.

Here, Google Translate translated the base verb of the VPC anpflanzen to plant, which corresponds to the translation of pflanzen. The VPC's particle was apparently interpreted as the preposition to. Furthermore, Google encountered problems translating Chilis, as this word should not be written with a capital letter in English and the commonly used plural form would be chillies, chilies, or chili peppers. Bing Translator managed to translate the noun correctly, but simply ignored the particle and only translated the base verb, providing a much better translation than Google, even though to grow would have been a more accurate choice of word.

Der Lehrer führt das Vorgehen an einem Beispiel vor.

Google: The teacher leads the procedure before an example.

Bing: The teacher introduces the approach with an example. 


\begin{tabular}{lrrrrrr}
\hline & \multicolumn{3}{c}{ Google } & & \multicolumn{1}{c}{ Bing } \\
& Sentence (\%) & Verb (\%) & Base V. $(\%)$ & Sentence $(\%)$ & Verb(\%) & Base V. (\%) \\
\hline VPC & $56(47.5 \%)$ & $83(70.3 \%)$ & $112(94.9 \%)$ & $46(39.0 \%)$ & $86(72.9 \%)$ & $109(92.4 \%)$ \\
Finite & $24(40.7 \%)$ & $35(59.3 \%)$ & $57(96.6 \%)$ & $23(39.0 \%)$ & $45(76.3 \%)$ & $57(96.6 \%)$ \\
Infinitive & $32(54.2 \%)$ & $48(81.4 \%)$ & $55(93.2 \%)$ & $23(39.0 \%)$ & $41(69.5 \%)$ & $52(88.1 \%)$ \\
\hline Simplex & $63(53.4 \%)$ & $108(91.5 \%)$ & $108(91.5 \%)$ & $63(53.4 \%)$ & $106(89.8 \%)$ & $106(89.8 \%)$ \\
Finite & $28(47.5 \%)$ & $51(86.4 \%)$ & $51(86.4 \%)$ & $32(54.2 \%)$ & $54(91.5 \%)$ & $54(91.5 \%)$ \\
Infinitive & $35(59.3 \%)$ & $57(96.6 \%)$ & $57(96.6 \%)$ & $31(52.5 \%)$ & $52(88.1 \%)$ & $52(88.1 \%)$ \\
\hline Total & $119(50.4 \%)$ & $191(80.9 \%)$ & $220(93.2 \%)$ & $109(46.2 \%)$ & $192(81.4 \%)$ & $215(91.1 \%)$ \\
\hline
\end{tabular}

Table 3: Separate results for Google Translate and Bing Translator; absolute numbers with percentages in brackets. Sentence $=$ correctly translated sentences, Verb $=$ correctly translated verbs, Base V. $=$ correctly translated base verbs, Simplex $=$ sentences containing simplex verbs, VPC $=$ sentences containing VPCs, Finite $=$ sentences where the target verb is finite, Infinitive $=$ sentences where the target verb is in the infinitive.

This example shows another too literal translation of the idiomatic VPC vorführen (to show, to demonstrate). Google's translation system translated the base verb führen as to lead and the separated particle vor as the preposition before. Bing managed to translate vorführen to to introduce which could be correct in a certain context. However, in other cases this would be an inaccurate or even incorrect translation, for example if that teacher demonstrated the approach for the second time. It might be that Bing drew a connection to the similar VPC einführen which would be a suitable translation for to introduce.

Er macht schon wieder blau.

Google: He's already blue.

Bing: He is again blue.

In this case, the particle of the VPC blaumachen (to play truant, to throw a sickie) was translated as if it were the adjective blau (blue). Since $\mathrm{He}$ makes blue again is not a valid English sentence, the language model of the translation system probably took a less probable translation of machen (to do, to make) and translated it to the third person singular form of to be.

These results imply that both translation systems rely too much on translating the base verb that underlies a VPC, as well as its particle separately instead of resolving their connection first. While this would still be a working approach for compositional constructions such as wegrennen (to run away), this procedure causes the translations of idiomatic VPCs like einlegen (to pickle) to be incorrect.

\section{Conclusions}

This paper presented an analysis of how VPCs affect translation quality in SMT. We illustrated the similarities and differences between English and German VPCs. In order to investigate how these differences influence the quality of SMT systems, we collected a set of 59 verb pairs, each consisting of a German VPC and a simplex verb that are synonyms. Then, we constructed a test suite of 118 sentences in which the simplex verb and VPC are completely substitutable and analysed the resulting English translations in Google Translate and Bing Translator. The results showed that especially separated VPCs can affect the translation quality of SMT systems and cause different kinds of mistakes, such as too literal translations of idiomatic expressions or the omittance of particles. The test suite that was created in the process of this study is made accessible online, thus providing a valuable resource for future research in this field.

This study focused on the identification and analysis of issues in translating texts that contain VPCs. Therefore, practical solutions to tackle these problems were not in the scope of this project, but would certainly be an interesting topic for future work. For instance, the work of Collins et al. (2005) and Holmqvist et al. (2012) could be used as a foundation for future research on how to avoid literal translations of VPCs by doing some kind of reordering first, to avoid errors caused by the translations system not being able to identify the base verb and the particle to be connected.

Furthermore, the sentences used in this work were rather simple and certainly did not cover all the possible issues that can be caused by VPCs, 
since the data was created manually by one person. Therefore, it would be desirable to compile a more realistic dataset to be able to analyse the phenomenon of VPCs more thoroughly, as well as employing additional people to ensure the quality of both, the dataset and the evaluation.

Moreover, it would be important to see the influence of other grammatical alternations of VPCs as well, as we only covered auxiliary infinitive constructions and finite forms in this study. Another interesting aspect to analyse in more detail would be if some of the errors are specifically related to only one class of VPCs, e.g., if idiomatic VPCs perform worse than compositional and aspectual ones. However, this would again require a revised dataset, where the proportion of each of the three verb classes is about the same to ensure comparability. In this study, the proportion of VPCs that exhibited an at least slightly idiomatic meaning was higher than for the other two verb classes.

Finally, it would be interesting to see if the results also apply to other language pairs where VPCs can be found, as well as to change the translation direction and investigate if it is an even greater challenge to translate English VPCs into German, considering that it is presumably harder to predict the correct position of verb and particle.

\section{References}

Heike Behrens. How difficult are complex verbs? Evidence from German, Dutch and English. Linguistics, 36(4):679-712, 1998.

Niladri Chatterjee and Renu Balyan. Context Resolution of Verb Particle Constructions for English to Hindi Translation. In Helena Hong Gao and Minghui Dong, editors, PACLIC, pages 140-149. Digital Enhancement of Cognitive Development, Waseda University, 2011.

Michael Collins, Philipp Koehn, and Ivona Kucerov. Clause restructuring for statistical machine translation. In Proceedings of the 43rd Annual Meeting on Association for Computational Linguistics, ACL'05, pages 531-540, Stroudsburg, PA, USA, 2005. Association for Computational Linguistics.

Nicole Dehé. Particle Verbs in English: Syntax, Information Structure, and Intonation. John Benjamins Publishing Co, 2002.

Maria Holmqvist, Sara Stymne, Lars Ahrenberg, and Magnus Merkel. Alignment-based reordering for SMT. In Nicoletta Calzolari (Conference Chair), Khalid Choukri, Thierry Declerck, Mehmet Uur Doan, Bente Maegaard, Joseph Mariani, Jan Odijk, and Stelios Piperidis, editors, Proceedings of the Eight International Conference on Language Resources and Evaluation, LREC'12, Istanbul, Turkey, 2012. European Language Resources Association (ELRA).

Su Nam Kim and Timothy Baldwin. How to Pick out Token Instances of English Verb-Particle Constructions. Language Resources and Evaluation, 44(12):97-113, 2010.

Stefan Müller. Syntax or morphology: German particle verbs revisited. In Nicole Dehé, Ray Jackendoff, Andrew McIntyre, and Silke Urban, editors, VerbParticle Explorations, volume 1 of Interface Explorations, pages 119-139. Mouton de Gruyter, 2002.

Ivan A. Sag, Timothy Baldwin, Francis Bond, Ann Copestake, and Dan Flickinger. Multiword Expressions: A Pain in the Neck for NLP. In Proceedings of the Third International Conference on Computational Linguistics and Intelligent Text Processing, CICLing'02, pages 1-15, 2002.

Aline Villavicencio. The availability of verb-particle constructions in lexical resources: How much is enough? Computer Speech \& Language, 19(4):415-432, 2005.

\section{Appendix A. Verb Pairs}

antworten - zurückschreiben; bedecken - abdecken; befestigen - anbringen; beginnen anfangen; begutachten - anschauen; beruhigen - abregen; bewilligen - zulassen; bitten einladen; demonstrieren - vorführen; dulden zulassen; emigrieren - auswandern; entkommen - weglaufen; entkräften - auslaugen; entscheiden - festlegen; erlauben - zulassen; erschießen abknallen; erwähnen - anführen; existieren vorkommen; explodieren - hochgehen; fehlen - fernbleiben; entlassen - rauswerfen; fliehen wegrennen; imitieren - nachahmen; immigrieren - einwandern; inhalieren - einatmen; kapitulieren - aufgeben; kentern - umkippen; konservieren - einlegen; kultivieren - anbauen; lehren beibringen; öffnen - aufmachen; produzieren - herstellen; scheitern - schiefgehen; schließen - ableiten; schwänzen - blaumachen; sinken abnehmen; sinken - untergehen; spendieren ausgeben; starten - abheben; sterben - abkratzen; stürzen - hinfallen; subtrahieren - abziehen; tagen - zusammenkommen; testen - ausprobieren; überfahren - umfahren; übergeben - aushändigen; übermitteln - durchgeben; unterscheiden - auseinanderhalten; verfallen - ablaufen; verjagen - fortjagen; vermelden - mitteilen; verreisen wegfahren; verschenken - weggeben; verschieben 
- aufschieben; verstehen - einsehen; wachsen

- zunehmen; wenden - umdrehen; zerlegen auseinandernehmen; züchten - anpflanzen.

URL to test suite:

http://stp.lingfil.uu.se/ ninas/testsuite.txt 